\title{
American National Standard
}

Adopted for Use by

the Federal Government

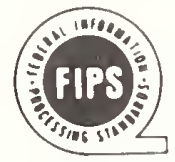

FIPS PUB 1-2

See Nolice on Inside Front Cover graphic representation of the control characters of american national standard code for information interchange 
This standard has been adopted for Federal Government use.

Details concerning its use within the Federal Government are contained in Federal Information Processing Standards Publication 1-2, Code for Information Interchange, Its Representations, Subsets, and Extensions. For a complete list of the publications available in the Federal Information Processing Standards Series, write to the Standards Processing Coordinator (ADP), Institute for Computer Sciences and Technology, National Bureau of Standards, Gaithersburg, MD 20899. 


\section{American National Standard Graphic Representation of the Control Characters of American National Standard Code for Information Interchange}

Secretariat

Computer and Business Equipment Manufacturers Association

Approved July 3, 1973

American National Standards Institute, Inc 
American

National

Standard

An American National Standard implies a consensus of those substantially concerned with its scope and provisions. An American National Standard is intended as a guide to aid the manufacturer, the consumer, and the general public. The existence of an American National Standard does not in any respect preclude anyone, whether he has approved the standard or not, from manufacturing, marketing, purchasing, or using products, processes, or procedures not conforming to the standard. American National Standards are subject to periodic review and users are cautioned to obtain the latest editions.

CAUTION NOTICE: This American National Standard may be revised or withdrawn at any time. The procedures of the American National Standards Institute require that action be taken to reaffirm, revise, or withdraw this standard no later than five years from the date of publication. Purchasers of American National Standards may receive current information on all standards by calling or writing the American National Standards Institute.

Published by

\section{American National Standards Institute 1430 Broadway, New York, New York 10018}

Copyrght @ 1973 by American National Standards Instrtute. Inc All rights reserved.

No part of this publication may he reproduced in any form. in an electronte retrieval system or otherwise, without

the pron written permasion of the publablier.

Printed in the United States of America

A $21 / 2 \mathrm{M} 685 / 5$ 
American National Standard Code for Information Interchange (ASC11) was first issued in 1963 and then published twice again with minor revisions as X3.4-1967 and X3.4-1968. Since then, it was found that in certain applications there is a need for a graphic representation of the normally nonprinting control characters. Different proposals for a pictorial representation were considered and exchanged with the European Computer Manufacturers Association (ECMA), Technical Committee 1. At the same time, the Deutscher Normenausschuss (DNA) proposed an alphanumeric abbreviation. That work was also considered in the development of the present standard.

Suggestions for improvement of this standard will be welcome. They should be sent to the American National Standards Institute, 1430 Broadway, New York, N.Y. 10018.

This standard was processed and approved for submittal to ANSI by American National Standards Committee on Computers and Information Processing, X3. Committee approval of the standard does not necessarily imply that all committee members voted for its approval. At the time it approved this standard, the X3 Committee had the following members:

\section{A. Phillips, Chairman \\ V. E. Henriques, Vice-Chairman \\ Robert M. Brown, Secretary}

Organization Represented

Addressograph Multigraph Corporation.

Air Transport Association.

American Bankers Association

American Gas Association .

American Institute of Certified Public Accountants.

American Library Association.

American Newspaper Publishers Association.

American Society of Meclanical lingineers.

Association for Computing Machinery.

Association of Americ on Railroads.

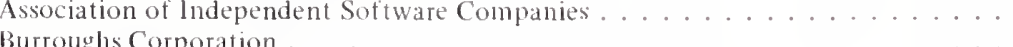

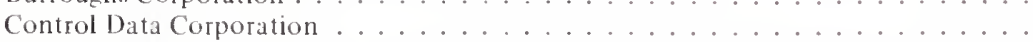

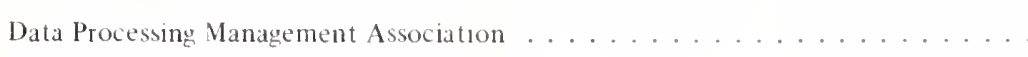

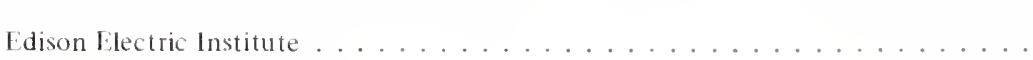

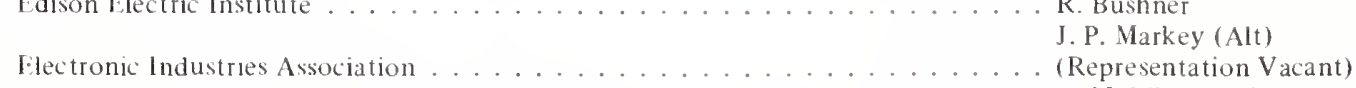

General l:lectric Company A. M. Wilson (Alt)

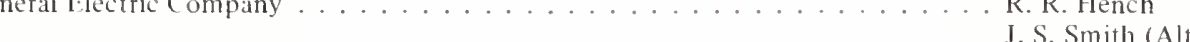

General Services Administration . . . . . . . . . . . . . . . D. L. Shoemaker

J. E. Rice (Alt)

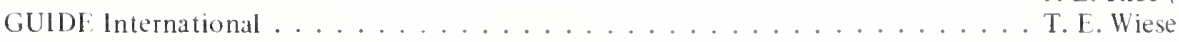

H. Seidensticker (Alt)

Honeywell Information Systems Inc ....................... Mc Namara

Eric H. Clamons (Alt)

Institute of Electrical and Electronics Engıneers, Communications Society . . . . . R. Gibbs

Institute of Electrical and Electronics Engineers, Computer Society . . . . . . . . C. W. Rosenthal

G. C. Schutz (Alt) 


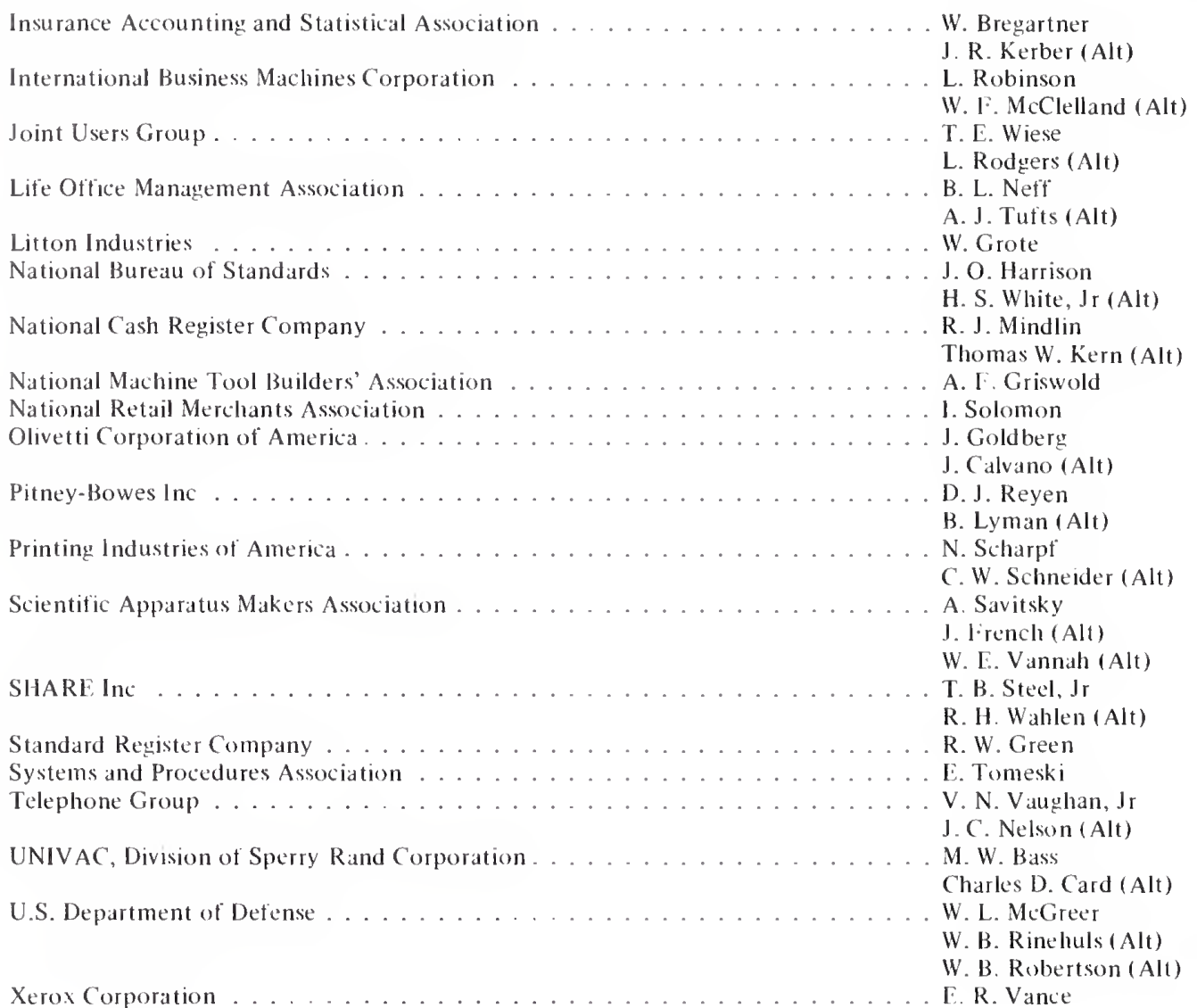


Subcommittee X3-L2 on Character Codes, which developed this standard, had the following members:

Eric H. Clamons, Chairman

Charles D. Card, Vice-Chairman

\author{
A. H. Beaver \\ Theodore R. Boosquet \\ John B. Booth \\ Royce L. Calloway \\ Clarence C. Chandler \\ L. J. Clingman \\ Blanton C. Duncan \\ Stanley R. Erdreich \\ T. F. I.itzsimmons \\ S. M. Garland \\ R. Guenther \\ Lothar I: Haas, Jr \\ Marjorie I: Hill \\ Thomas O. Holtey \\ William F. Hut \\ H. F. Ickes \\ William F. Keenan \\ Thomas W. Kern \\ John L. Little \\ Herbert S. Meltzer \\ Charles Navoichick \\ I red W. Smith \\ Vern L. Thompson
}

1. Scope ...................................... 6

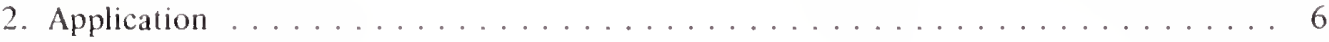

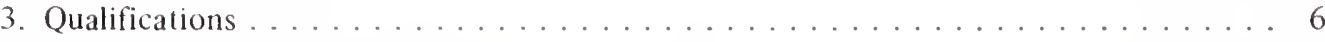

4. Standard Graphic Representations ...................... . 7

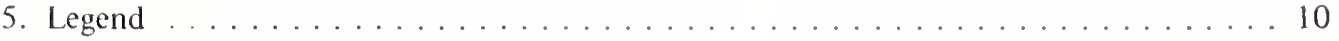

5.1 Control Characters ............................... 10

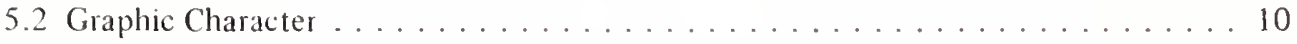

Appendıx Font Design Considerations for the Alphanumeric Representations ....... 10

Table Al Dot Pattern Representation . . . . . . . . . . . . . . . . . . 11-12 


\section{American $\mathbf{N}$ ational $\mathbf{S t a n d a r d}$ \\ Graphic Representation of \\ the Control Characters of \\ American $\mathbf{N}$ ational $\mathbf{S t a n d}$ ard \\ Code for Information Interchange}

\section{Scope}

1.1 This standard provides a graphic representation of the control characters given in columns 0 and I of the Standard Code table contained in American National Standard Code for Information Interchange, X3.4-1968 (ASCII). It also provides for the normally nonprinting character SPACE (position 2/0 of the ASCII table) and for the character DELETE (position 7/I5 of the ASCII table).

1.2 The standard contains two alternative sets of representations: a pictorial representation and an alphanumeric representation.

\section{Application}

These representations are intended for use in the display of control characters on devices, where the graphic representation of these normally nonprinting characters is required. Among the devices included are paper tape punches, diagnostic printers, and cathode-ray tube devices.

\section{Qualifications}

3.1 There may be no need to implement all symbols.

3.2 Each pictorial or alphanumeric representation is to be considered as a single symbol. It may occupy either one or more than one position on a printed or displayed line, depending on the implementation. Pictorial and alphanumeric representation may be intermixed in a single display.

3.3 The precise font design for the symbols is not a part of the standard.

3.4 This standard does not abrogate the use of the three claracter abbreviations defined in ASCll for applications where they are desired.

3.5 While optical recognition of the graphic representations given in this standard may be feasible, machine readability was not an objective of the standard. 
4. Standard Graphic Representations

\begin{tabular}{|c|c|c|c|}
\hline Code Position & Character & $\begin{array}{c}\text { Pictorial } \\
\text { Representation }\end{array}$ & $\begin{array}{l}\text { Alphanumeric } \\
\text { Representation }\end{array}$ \\
\hline $0 / 0$ & NUL & & \\
\hline $0 / 1$ & $\mathrm{SOH}$ & & \\
\hline $0 / 2$ & STX & & \\
\hline $0 / 3$ & ETX & & \\
\hline $0 / 4$ & EOT & & \\
\hline $0 / 5$ & ENQ & & \\
\hline $0 / 6$ & ACK & & AK \\
\hline $0 / 7$ & BEL & & B L \\
\hline $0 / 8$ & $B S$ & & BS \\
\hline $0 / 9$ & $H T$ & & $\mathrm{HT}$ \\
\hline $0 / 10$ & LF & & LF \\
\hline
\end{tabular}

NOTE: The pictorial representation of $0 / 5$ is a schematic representation of which may also be used when equipment allows. 


\begin{tabular}{|c|c|c|c|}
\hline Code Position & Character & $\begin{array}{c}\text { Pictorial } \\
\text { Representation }\end{array}$ & $\begin{array}{l}\text { Alphanumeric } \\
\text { Representation }\end{array}$ \\
\hline $0 / 11$ & $V T$ & & \\
\hline $0 / 12$ & $F F$ & & \\
\hline $0 / 13$ & CR & & \\
\hline $0 / 14$ & $\mathrm{SO}$ & & \\
\hline $0 / 15$ & SI & & \\
\hline $1 / 0$ & DLE & & \\
\hline $1 / 1$ & DC1 & & \\
\hline $1 / 2$ & $\mathrm{DC} 2$ & & \\
\hline $1 / 3$ & DC3 & & \\
\hline $1 / 4$ & DC4 & & \\
\hline $1 / 5$ & NAK & & NK \\
\hline $1 / 6$ & SYN & & SY \\
\hline
\end{tabular}




\begin{tabular}{|c|c|c|c|}
\hline Code Position & Character & $\begin{array}{c}\text { Pictorial } \\
\text { Representation }\end{array}$ & $\begin{array}{l}\text { Alphanumeric } \\
\text { Representation }\end{array}$ \\
\hline $1 / 7$ & ETB & & EB \\
\hline $1 / 8$ & CAN & & \\
\hline $1 / 9$ & EM & & EM \\
\hline $1 / 10$ & SUB & & SB \\
\hline 111 & ESC & & EC \\
\hline $1 / 12$ & FS & & \\
\hline 113 & GS & & 65 \\
\hline 114 & RS & & RS \\
\hline 115 & US & & 00 \\
\hline $2 / 0$ & SP & & SP \\
\hline $7 / 15$ & DEL & & DT \\
\hline
\end{tabular}


5. Legend

\begin{tabular}{|c|c|c|c|}
\hline \multicolumn{4}{|c|}{1 Control Characters } \\
\hline NUL & Null & DLE & Data Link Escape (CC) \\
\hline $\mathrm{SOH}$ & Start of Heading (CC) & $\mathrm{DC1}$ & Device Control 1 \\
\hline STX & Start of Text (CC) & DC2 & Device Control 2 \\
\hline ETX & End of Text (CC) & DC3 & Device Control 3 \\
\hline EOT & End of Transmission (CC) & $\mathrm{DC} 4$ & Device Control 4 (Stop) \\
\hline ENO & Enquiry (CC) & NAK & Negative Acknowledge (CC) \\
\hline ACK & Acknowledge (CC) & SYN & Synchronous Idle (CC) \\
\hline$B E L$ & Bell (audible or attention signal) & ETB & End of Transmission Block (CC) \\
\hline BS & Backspace (FE) & CAN & Cancel \\
\hline HT & Horizontal Tabulation (punched card skip) (FE) & EM & End of Medium \\
\hline LF & Line Feed (FE) & SUB & Substitute \\
\hline VT & Vertical Tabulation (FE) & ESC & Escape \\
\hline $\mathrm{FF}$ & Form Feed (FE) & FS & File Separator (IS) \\
\hline CR & Carriage Return (FE) & GS & Group Separator (IS) \\
\hline so & Shift Out & RS & Record Separator (IS) \\
\hline $\mathrm{SI}$ & Shift In & US & Unit Separator (IS) \\
\hline & & DEL & Delete ${ }^{1}$ \\
\hline
\end{tabular}

\subsection{Graphic Character \\ SP Space (normally nonprinting) \\ NOTE: $\mathrm{CC}$ - Communication Control \\ FE - Format Effector \\ IS - Information Separator}

${ }^{1}$ In the strict sense, DEL is not a control character.

\section{A 99 end ix (This Appendix is not a part of American National Standard Graphic Representation of the Control Char- acters of American National Standard Code for Information Interchange, X3.32-1973, but is included for information purposes only.)}

\section{Font Design Considerations for the Alphanumeric Representations}

\section{A1. $7 \times 9$ Dot Pattern}

The $7 \times 9$ dot pattern representation given in Table $\mathrm{Al}$ illustrates the feasibility of implementing the standard. It can also be used as a guide for designing vectorgenerated or hard-type character representations.

\section{A2. $5 \times 7$ Dot Pattern}

The $5 \times 7$ dot pattern representation given in Table Al illustrates the feasibility of reducing the entropy required to form the characters and still retain legibility.

\section{A3. Meaning of Symbols}

Symbols selected in pictorial representations are similar to some currently in use in five-level applications. They should cause no ambiguity, since their meaning can be easily derived from the context in which they are used.

\section{A4. Criteria for Symbols}

Symbols were chosen to be: (1) clearly printable by impact printers, (2) clearly displayable by matrix devices, (3) interpretable with no ambiguity, and (4) suggestive of the control function to be performed. Not all of these criteria were met for all symbols; however, the best possible compromise was adopted. 
Table Al

Dot Pattern Representation

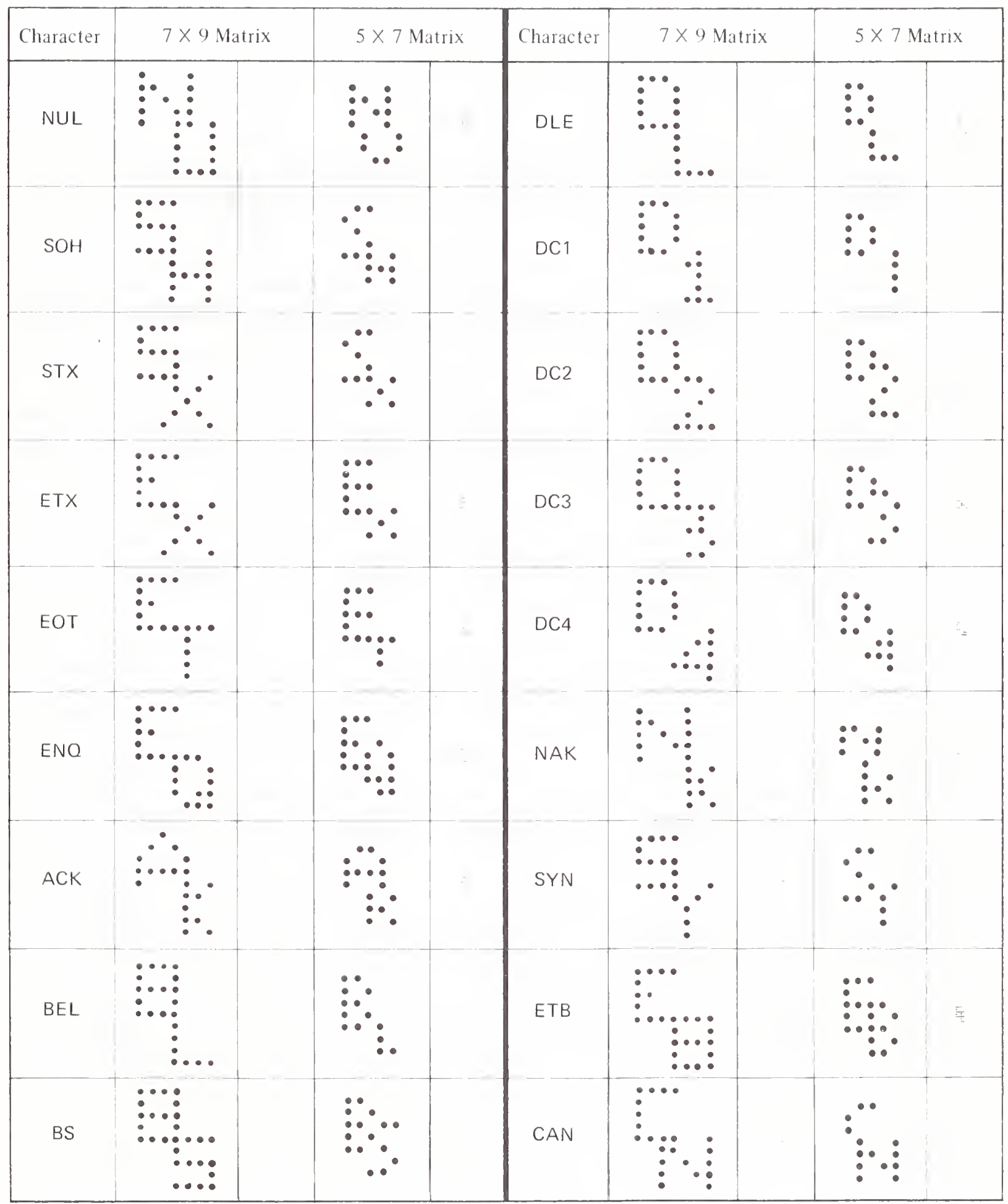

(Contmued on next page) 
Table A1 - Conimued

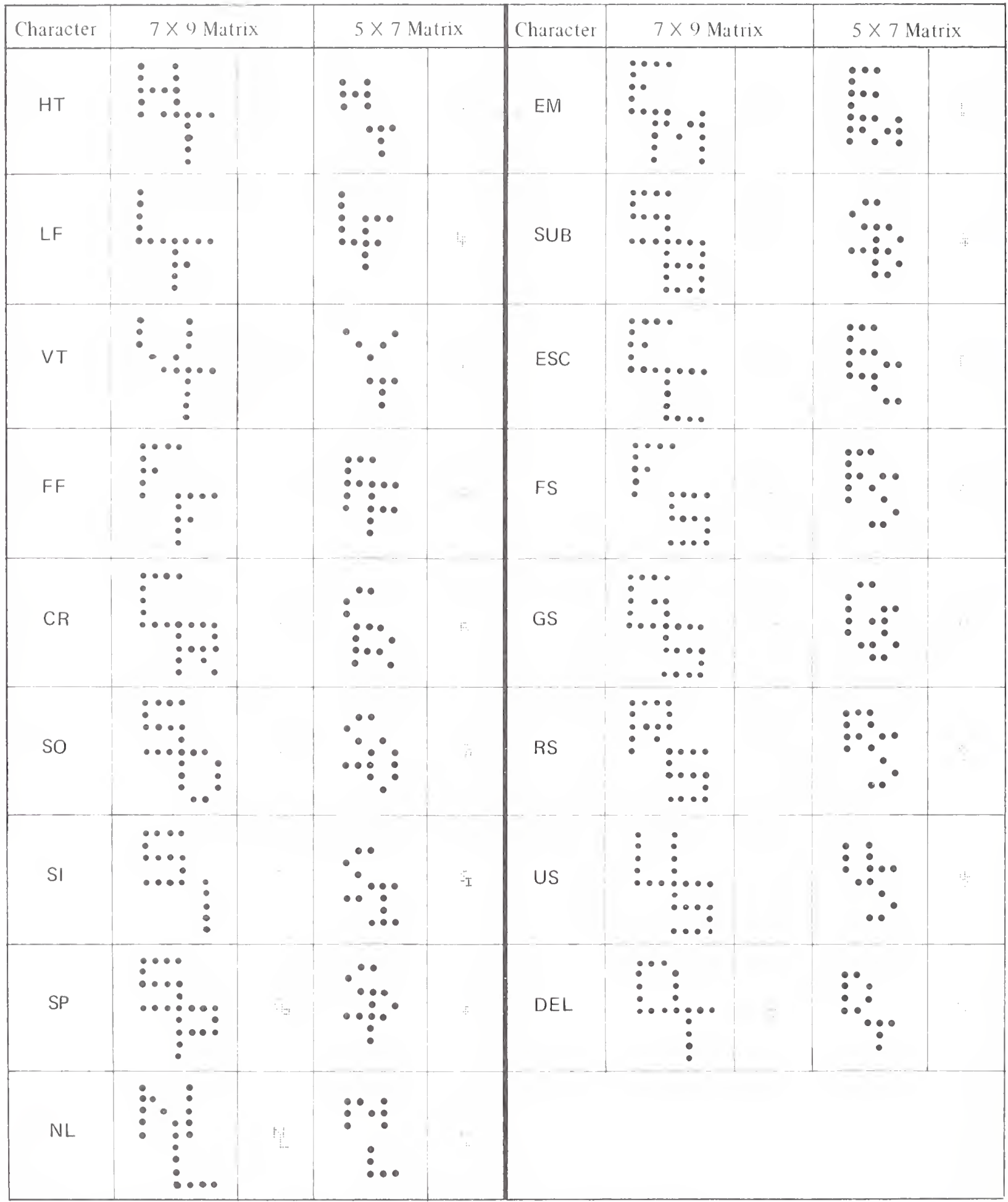

NOTE: NL is the abbreviation for New Line, which is defined in ASCII as an alternate defintton to the code for Line leed (L.F). Its graphic representation in this table is for information only. 
X3.115-1984 Unformatted 80 Megabyte Trident Pack for Use at 370 tpi and 6000 bpi (General, Physical, and Magnetic Characteristics)

X3.117-1984 Printable/Image Areas for Text and Facsimile Communication Equipment

X3.118-1984 Financial Services - Personal Identification Number - PIN Pad

X3.119-1984 Contact Start/Stop Storage Disk, 158361 Flux Trans itions per Track, 8.268 Inch $(210 \mathrm{~mm})$ Outer Diameter and 3.937 inch $(100 \mathrm{~mm})$ Inner Diameter

X3.120-1984 Contact Start/Stop Storage Disk

X3.121-1985 Two-Sided, Double-Density, Unformatted 5.25-inch $(130-\mathrm{mm}), 48$-tpi (1,9-tpmm). Flexible Disk Cartridge for 7958 bpr Use
X11.1-1977 Programming Language MUMPS

IEEE 416-1978 Abbreviated Test Language for All Systems

(ATLAS)

IEEE 716-1982 Standard C/ATLAS Language

IEEE 717-1982 Standard C/ATLAS Syntax

IEEE 770 X3.97-1983 Programming Language PASCAL

IEEE 771-1980 Guide to the Use of ATLAS

MIL-STD-1815A-1983 Reference Manual for the Ada Programming Language

X3/TRI-82 Dictionary for Information Processing Systems (Technical Report) 


\section{American National Standards for Information Processing}

X3.1-1976 Synchronous Signaling Rates for Data Transmission X3.2-1970 Print Specifications for Magnetic Ink Character

Recognition

X3.4-1977 Code for Information Interchange

X3.5-1970 Flowchart Symbols and Their Usage

X3.6.1965 Perforated Tape Code

X3.9-1978 Programming Language FORTRAN

X3.11-1969 General Purpose Paper Cards

X3.14-1983 Recorded Magnetic Tape (200 CPI, NRZI)

X3.15-1976 Bit Sequencing of the American National Standard

Code for Information Interchange in Serial-by-Bit Data Transmission

X3.16-1976 Character Structure and Character Parity Sense for

Serial-by-Bit Data Communication in the American National Standard Code for Information Interchange

X3.17-1981 Character Set for Optical Character Recognition (OCR-A)

X3.18-1974 One-Inch Perforated Paper Tape

X3.19-1974 Eleven-Sixteenths-Inch Perforated Paper Tape

X3.20-1967 Take-Up Reels for One-Inch Perforated Tape

X3.21-1967 Rectangular Holes in Twelve-Row Punched Cards

X3.22-1983 Recorded Magnetic Tape (800 CPI, NRZI)

X3.23.1974 Programming Language COBOL

X3.25-1976 Character Structure and Character Parity Sense for Parallel-by-Bit Data Communication in the American National

Standard Code for Information Interchange

X3.26-1980 Hollerith Punched Card Code

X3.27-1978 Magnetic Tape Labels and File Structure

X3.28-1976 Procedures for the Use of the Communication Control Characters of American National Standard Code for Information Interchange in Specified Data Communication Links

X3.29.1971 Specifications for Properties of Unpunched Oiled Paper Perforator Tape

X3.30-1971 Representation for Calendar Date and Ordinal Date

X3.31.1973 Structure for the Identification of the Counties of the United States

X3.32-1973 Graphic Representation of the Control Characters of American National Standard Code for Information Interchange X3.34-1972 Interchange Rolls of Perforated Tape

X3.36-1975 Synchronous High-Speed Data Signaling Rates between Data Terminal Equipment and Data Communication Equipment

X3.37.1980 Programming Language APT

X3.38-1972 Identification of States of the United States

(Including the District of Columbia)

X3.39-1973 Recorded Magnetic Tape (1600 CPI, PE)

X3.40-1983 Unrecorded Magnetic Tape (9-Track 800 CPI, NRZI;

$1600 \mathrm{CPI}, \mathrm{PE}$; and $6250 \mathrm{CPI}, \mathrm{GCR}$ )

X3.41-1974 Code Extension Techniques for Use with the 7-Bit

Coded Character Set of American National Standard Code for Information Interchange

X3.42-1975 Representation of Numeric Values in Character Strings X3.43-1977 Representations of Local Time of the Day

X3.44-1974 Determination of the Performance of Data Communication Systems

X3.45-1982 Character Set for Handprinting

X3.46-1974 Unrecorded Magnetic Six-Disk Pack (General, Physical, and Magnetic Characteristics)

X3.47-1977 Structure for the Identification of Named Populated Places and Related Entities of the States of the United States for Information Interchange

X3.48-1977 Magnetic Tape Cassettes (3.810-mm [0.150-Inch]

Tape at $32 \mathrm{bpmm}$ [800 bpi] , PE)

X3.49-1975 Character Set for Optical Character Recognition (OCR-B) X3.50-1976 Representations for U.S. Customary, SI, and Other Units to Be Used in Systems with Limited Character Sets

X3.51-1975 Representations of Universal Time, Local Time Differentials, and United States Time Zone References

X3.52-1976 Unrecorded Single-Disk Cartridge (Front Loading, 2200 BPI) (General, Physical, and Magnetic Requirements)

X3.53-1976 Programming Language PL/I

X3.54-1976 Recorded Magnetic Tape (6250 CPI, Group Coded Recording)

X3.55-1982 Unrecorded Magnetic Tape Cartridge, 0.250 Inch $(6.30 \mathrm{~mm}), 1600$ bpi (63 bpmm), Phase encoded

X3.56-1977 Recorded Magnetic Tape Cartridge, 4 Track, 0.250

Inch $(6.30 \mathrm{~mm}), 1600$ bpi $(63 \mathrm{bpmm})$, Phase Encoded
X3.57-1977 Structure for Formatting Message Headings Using the American National Standard Code for Information Interchange for Data Communication Systems Control

X3.58-1977 Unrecorded Eleven-Disk Pack (General, Physical, and Magnetic Requirements)

X3.59-1981 Magnetic Tape Cassettes, Dual Track Complementary Return-to-Bias (CRB) Four-States Recording on 3.81 -mm 10.150 . Inch) Tape

X3.60-1978 Programming Language Minimal BASIC

X3.61-1978 Representation of Geographic Point Locations

X3.62.1979 Paper Used in Optical Character Recognition (OCR) Systems

X3.63-1981 Unrecorded Twelve-Disk Pack (100 Megabytes) (General, Physical, and Magnetic Requirements)

X3.64-1979 Additional Controls for Use with American National Standard Code for Information Interchange

X3.66-1979 Advanced Data Communication Control Procedures (ADCCP)

X3.72-1981 Parallel Recorded Magnetic Tape Cartridge, 4 Track, 0.250 Inch $(6.30 \mathrm{~mm}), 1600$ bpi $(63 \mathrm{bpmm})$, Phase Encoded X3.73-1980 Single-Sided Unformatted Flexible Disk Cartridge (for 6631-BPR Use)

X3.74-1981 Programming Language PL/I, General-Purpose Subset X3.76-1981 Unformatted Single-Disk Cartridge (Top Loading, 200 tpi 4400 bpi) (General, Physical, and Magnetic Requirements) X3.77-1980 Representation of Pocket Select Characters

X3.78-1981 Representation of Vertical Carriage Positioning Characters in Information Interchange

X3.79-1981 Determination of Performance of Data Communica. tions Systems That Use Bit-Oriented Communication Procedures X3.80-1981 Interfaces between Flexible Disk Cartridge Drives and Their Host Controllers

X3.82-1980 One-Sided Single-Density Unformatted 5.25-Inch

Flexible Disk Cartridge (for 3979-BPR Use)

X3.83-1980 ANSI Sponsorship Procedures for ISO Registration According to ISO 2375

X3.84-1981 Unformatted Twelve-Disk Pack (200 Megabytes) (General, Physical, and Magnetic Requirements)

X3.85-1981 1/2-Inch Magnetic Tape Interchange Using a Self

Loading Cartridge

X3.86-1980 Optical Character Recognition (OCR) Inks

X3.88-1981 Computer Program Abstracts

X3.89-1981 Unrecorded Single-Disk, Double-Density Cartridge

(Front Loading, 2200 bpi, 200 tpi) (General, Physical, and Mag. netic Requirements)

X3.91M-1982 Storage Module Interfaces

X3.92-1981 Data Encryption Algorithm

X3.93M-1981 OCR Character Positioning

X3.95-1982 Microprocessors - Hexadecimal Input/Output, Using 5-Bit and 7-Bit Teleprinters

X3.96-1983 Continuous Business Forms (Single-Part)

X3.98-1983 Text Information Interchange in Page Image Format (PIF)

X3.99-1983 Print Quality Guideline for Optical Character Recognition (OCR)

X3.100-1983 Interface Between Data Terminal Equipment and Data Circuit-Terminating Equipment for Packet Mode Operation with Packet Switched Data Communications Network

X3.101-1984 Interfaces Between Rigid Disk Drive(s) and Host(s)

X3.102-1983 Data Communication Systems and Services - UserOriented Performance Parameters

X3.103-1983 Unrecorded Magnetic Tape Minicassette for Information Interchange, Coplanar $3.81 \mathrm{~mm}(0.150 \mathrm{in})$

X3.104-1983 Recorded Magnetic Tape Minicassette for Information Interchange, Coplanar $3.81 \mathrm{~mm}(0.150 \mathrm{in})$. Phase Encoded X3.105-1983 Data Link Encryption

X3.106-1983 Modes of Operation for the Data Encryption Algorithm X3.110-1983 Videotex/Teletext Presentation Level Protocol Syntax $\times 3.112-1984$ 14-in (356-mm) Diameter Low-Surface-Friction Magnetic Storage Disk

X3.114-1984 Alphanumeric Machines; Coded Character Sets for Keyboard Arrangements in ANSI X4.23-1982 and X4.22-1983

(continued on reverse) 